\title{
Current cloud challenges in Germany: the perspective of cloud service providers
}

\author{
Raoul Hentschel', Christian Leyh and Anne Petznick
}

\begin{abstract}
Cloud computing has a significant impact on information and communication technology (ICT) and is one of the most important technological drivers of the digitalization of enterprises. However, due to the increasing dissemination of cloud services and the growing number of cloud service providers (CSPs), the uncertainty and risks for user companies in adopting cloud services have also increased. In this paper, we address those aspects from the perspective of the CSPs. We identified relevant literature and studies and conducted interviews with business experts from 16 German CSPs. In our results, we present current customer requirements and barriers to using cloud services from a provider's viewpoint and identify the actions of and obstacles for CSPs in meeting the needs and constraints of the customers. Finally, we identify current and future challenges for CSPs in dealing with customer requirements and barriers by addressing their root causes. One of the main challenges from the CSPs' perspective is addressing customers appropriately and building relationships of trust. This also "forces" changes in the sales processes. In this process, the essential challenges can be identified as an increase in complexity and a simultaneous simplification of specific sales activities. Therefore, the necessity arises for the continuous support of business relationships through value-adding and additional services. However, this results in another challenge for the CSPs - Namely, to find the right balance between standardization and meeting customer-specific requirements. In our paper, we show that the perspective of the CSPs is rarely discussed in the literature. Nevertheless, understanding the perceptions of the providers and their actions and measures is essential for future research activities in the field of cloud service selection. Comparing the customers' perspectives and viewpoints with the CSPs' actions will enhance the development of a holistic selection approach for future cloud projects. Therefore, our paper's contribution to research is also the identification of this missing integration.
\end{abstract}

Keywords: Cloud computing, Cloud service provider, Cloud requirements, Cloud user

\section{Motivation}

Information and communication technologies (ICT) have been undergoing rapid changes for more than a decade and have an enormous impact on almost every aspect of daily life. Therefore, companies are faced with new challenges due to the radically increasing digitalization and digitization of the business environment. Regarding this development, cloud computing (CC) is one of the most important technological drivers. It has a significant impact on the digitalization of enterprises and requires changes in the Information Technology (IT) departments of organizations [1-6].

\footnotetext{
* Correspondence: Raoul.Hentschel@tu-dresden.de

Chair of Information Systems, esp., Information Systems in Manufacturing and Commerce, Technische Universität Dresden, Helmholtzstr. 10, 01069 Dresden, Germany
}

As a new possibility for IT sourcing, CC allows companies to gain access to a shared pool of managed and scalable IT resources on a rental basis (e.g., pay-per-use, pay-per-period). The resources (e.g., networks, servers, storage, applications, and services) are offered in a scalable way via the Internet without the need for any longterm capital expenditures or specific IT knowledge on the customer side [7-14]. Over the years, numerous definitions for CC have been established (e.g., see [13, 1517]). However, researchers have broadly adopted the CC definition of the National Institute of Standards and Technology (NIST), which specifies five essential characteristics (on-demand self-service, broad network access, resource pooling, rapid elasticity, and measured service), three service models (Software-as-a-Service [SaaS], Platform-as-a-Service [PaaS], and Infrastructure-as-a-Service [IaaS]), and four CC deployment models (private, public, community, and hybrid) [18]. 
However, $\mathrm{CC}$ has not simply arrived in the corporate world. Armbrust et al. [19] have already stated in 2009 that the "long-held dream of cloud computing" will transform a large part of the IT industry. In addition to the technical aspects that are associated with the virtualization of hardware, virtual data centers, and service models IaaS, PaaS, and SaaS [20], CC is destined to become more important and to have substantial effects on the IT market, primarily due to economically motivations [17, 21, 22]. Especially in the IT departments of large organizations, $\mathrm{CC}$ has become an everyday phenomenon [23-25].

In addition to the abovementioned technical characteristics of CC, several business aspects have emerged. Those aspects stem not only from the increasing trend towards service orientation but also cover opportunities for offering services on $\mathrm{CC}$ platforms and the possibilities of integrating individual component services with value-added services [26]. This has resulted in a complex value network of $\mathrm{CC}$, with different market players offering specific classes of services (see Fig. 1). In addition to the two primary entities, namely, cloud service providers (CSPs) that offer software applications, platforms or infrastructure for their cloud consumers, other roles have emerged. There are (cloud) consultants with in-depth knowledge of CC offerings and of the user companies' business processes and requirements, who identify and implement appropriate cloud services. Furthermore, there are aggregators that combine existing services into new value-added services for certain needs. This type of role is comparable to a value-added reseller. There are also integrators that support user companies in converting and migrating existing on-premise data into the cloud or preparing for the integration of a $\mathrm{CC}$ solution into existing IT landscapes [27].

German companies (in light of our cultural background) were initially doubtful and, therefore, reluctant to adopt CC. However, as of today, German companies have gained a wide range of experience in adopting and using cloud services [28]. Recent studies show that the number of CC user companies in Germany has been steadily increasing for several years [23, 29, 30]. According to a study by the auditing company KPMG in cooperation with the German Industry Association BITKOM, two out of three companies (65\%) had already deployed cloud services in 2016 and an additional 18\% had already planned to implement cloud services [29]. In another study, PricewaterhouseCoopers (PwC), in cooperation with the Professional Association Information Systems Audit and Control Association (ISACA), found that up to $69 \%$ of companies in Germany use CC [23]. According to an earlier study by $\mathrm{PwC}$, SaaS is the predominant model in this context, with communication, collaboration, and security applications being particularly popular [31]. As a result, for many organizations, it is no longer a question of whether $\mathrm{CC}$ is used; rather, the question is which $\mathrm{CC}$ model is suitable. Furthermore, companies must decide whether the acquisition and operation of cloud solutions will be complementary or substitutional to the company's existing IT resources [28].

However, due to the increasing proliferation of $\mathrm{CC}$ technologies and the growing number of CSPs worldwide and in the German market, the uncertainty and risks in adopting cloud services have also increased. A lack of trust in security and data protection, in addition

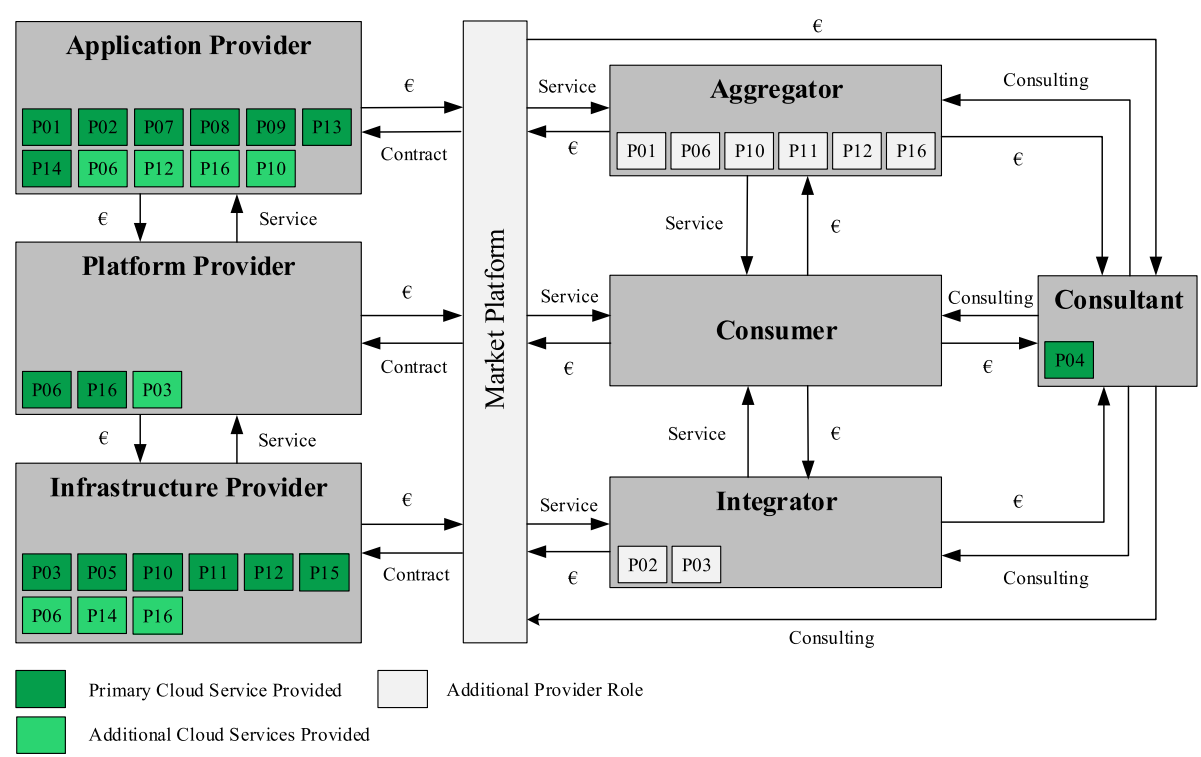

Fig. 1 Classification of companies in the value network of CC (adapted from [27]) 
to a heavy dependence on CSPs, are some of the fears and barriers that discourage companies from using cloud solutions [22, 32-41]. In addition, companies in the role of cloud consumers are confronted with the complex selection of a suitable cloud service and the appropriate CSP. This selection is affected by many factors, and the implementation and usage of $\mathrm{CC}$ have several implications and effects on the user companies.

However, it is questionable to what extent the CSPs are aware of the customer requirements, fears, needs, and constraints, and how and in which ways they are identifying and addressing these issues. Addressing these topics is one aspect of our research project. The main goal of our long-term research is to develop a tool for decision support in the CSP selection process by addressing the perspectives of both the user companies and the CSPs. Therefore, in this paper, we will investigate which customer requirements and barriers are perceived by the CSPs. Regarding this, we could not identify any detailed work that focuses the providers' perspective (see section 2). This is why we address the following three research questions $(\mathrm{RQ})$ in our research:

- RQ 1: What do CSPs perceive as the customer requirements for and barriers to cloud usage?

- RQ 2: What actions do CSPs take to address these requirements and barriers and what effects do these actions have on the sales process?

- RQ 3: What current and future challenges for CSPs can be identified from the CSPs' perspectives?

To answer these research questions, we use an exploratory research approach and set up an interview study. With this study, we want to investigate and identify the main challenges that CSPs need to address to meet customer requirements as best as possible. In particular, the focus of this study lies in identifying the customer-side barriers and risks that are associated with the use of the cloud from the CSPs' perspective. In addition, we want to identify the measures that are being applied in sales and the essential aspects for the creation of a trusting relationship with the customers to finally derive current and future challenges for CSPs.

As a first step in our research that is presented in this paper, we focused on CSPs in Germany to gain initial insights as a basis for the next steps in investigating the CSPs' perspective. Therefore, the paper is structured as follows: following this introduction, we provide an overview of related work and summarize prior literature in the field of CC to position our own work. Then, we describe our research design. After that, we provide as the main part of the paper selected results from the interview study. Finally, the paper concludes with a discussion and summary, where we elaborate upon various implications for practice and give an outlook on future research.

\section{Related work}

The selection factors and the implementation effects of $\mathrm{CC}$ have been widely discussed in prior applications and scientific research (e.g., [10, 34, 38, 41-57]).

However, research on how to promote and provide these services and what factors to consider from a provider perspective is scarce. Work that comes close to this considers the topic from a client or neutral perspective. With this in mind, we identified numerous requirement catalogs, classification schemes, criteria frameworks, etc., for the selection of appropriate cloud services and CSPs from conceptual and/or empirical investigations. Examples are listed in Table 1. They were

Table 1 Conceptual and empirical investigations for the selection of appropriate cloud services

\begin{tabular}{|c|c|c|}
\hline $\begin{array}{l}\text { Research Type/ } \\
\text { Stakeholder Focus }\end{array}$ & Phases & Reference \\
\hline Empirical/Customer & $\begin{array}{l}\text { Five factors influencing the cloud usage by SMEs - Ease of use \& convenience; Security \& privacy; Cost } \\
\text { reduction; Sharing \& collaboration; Reliability }\end{array}$ & $\begin{array}{l}\text { Gupta et al. } \\
{[55]}\end{array}$ \\
\hline Empirical/Customer & $\begin{array}{l}\text { Five categories - Information security; Performance \& usability; Costs; Support \& cooperation; Transparency \& } \\
\text { organization of the provider }\end{array}$ & $\begin{array}{l}\text { Hetzenecker et } \\
\text { al. [43] }\end{array}$ \\
\hline Conceptual/Customer & Proposal of a multi-attribute group decision-making method for CSP selection & Liu et al. [45] \\
\hline Conceptual/Customer & $\begin{array}{l}\text { Five factors - Relative advantage, Top management support, Firm size, Competitive pressure, Trading partner } \\
\text { pressure }\end{array}$ & Low et al. [52] \\
\hline Conceptual/Customer & $\begin{array}{l}\text { Three-tier classification framework with six target dimensions - Flexibility, Cost, Performance, IT security \& } \\
\text { compliance, Reliability \& trustworthiness, Service \& cloud management }\end{array}$ & $\begin{array}{l}\text { Repschläger et } \\
\text { al. [42] }\end{array}$ \\
\hline Conceptual/Customer & $\begin{array}{l}\text { Multi-criteria decision-making methods for CSP selection - Performance-based model, Finance-based model, } \\
\text { Security-based model }\end{array}$ & $\begin{array}{l}\text { Supriya et al. } \\
{[44]}\end{array}$ \\
\hline Conceptual/Customer & $\begin{array}{l}\text { Proposal of a holistic model for CSP selection - FAGI (Function, Auditability, Governability and } \\
\text { Interoperability) }\end{array}$ & $\begin{array}{l}\text { Tang and Liu } \\
{[34]}\end{array}$ \\
\hline Conceptual/Customer & 13 success factors -, e.g., Performance, Security, Compliance, Legal aspects, Flexibility & $\begin{array}{l}\text { Walther et al. } \\
{[50]}\end{array}$ \\
\hline
\end{tabular}


chosen because they are popular and well-cited articles or address our research area to a large extent.

As argued above, mostly the users' perspectives and the requirements from the user's/customer's point of view have been investigated for cloud service adoption and provider selection.

Furthermore, regarding German enterprises and the German cloud market, current studies have revealed that security requirements [58], data location in Germany or at least in the $\mathrm{EU}$, and individual adaptability of the cloud solution [29] are the most frequently mentioned requirements from a business perspective. In addition, German public institutions, such as the German Federal Office for Information Security (BSI), offer comprehensive decision-making support with criteria lists of which companies one should be aware of when selecting a CSP [59].

The cloud service market is highly competitive and CSPs face enormous challenges in positioning their services [60]. Hence, CSPs are now more than ever required to perceive customer requirements and to address the fears of potential customers with adequate services and further support to create additional value beyond simply selling the service. CSPs can proactively motivate endusers to shift towards CC, e.g., by communicating the benefits of $\mathrm{CC}$, alleviating security concerns about $\mathrm{CC}$, and lowering their switching costs $[53,60]$.

Communicating involves information events, online seminars, regular dialogues, and the exchange of information with clients. CSPs need to be aware of these customer requirements because they represent the body of challenges that CSPs must address to launch successful services [61]. By addressing the strategies and approaches of the user companies regarding CC, CSPs can identify and better understand the specific key requirements of their (future) customers [28]. Moreover, Hsu et al. [56] state that CSPs could benefit strongly from focusing more on promoting and validating the cloud benefits in the correct way than on marketing their services to potential early adopters since they found that perceived benefits are the most influential determinant of cloud adoption [56].

At this point, the existing CC literature still fails to address the providers' perspective, which is also revealed in several systematic literature reviews that focus on CC (e.g., $[5,13,14,49,62,63]$. Fewer research studies and publications address the abovementioned challenges and requirements by focusing on the CSPs and the providers' perception of the CC market. However, as also stated in several publications (e.g., [8, 31, 64, 65]), a key success factor for CSPs is the provision of the appropriate services.

Therefore, CSPs need to know and understand the customers' requirements to cover those requirements as best as possible and to address and manage end-user expectations appropriately. This is where our study comes in, by explicitly focusing on the CSPs' perspective and their perceptions.

\section{Study design}

Data collection methodology

Our study follows an exploratory research design to uncover requirements and barriers from a provider perspective. Therefore, we address CSPs, which were asked about requirements for and barriers to the use of cloud services. The primary goal is to gather information from several experts in this field. To ensure practical experience in the field of providing cloud services and proficient market knowledge, in the context of our investigation, experts had to work for CSPs either at a top management level or in a position with customer contact or broad market insight (such as sales or business development). Apart from having a high level of professional experience in providing cloud services, we chose interviewees so that we could cover a mix of companies from diverse business sectors and of different company sizes.

We decided to conduct a qualitative interview study because a qualitative approach considers the personal perceptions, motives, background, and experience of the experts in a more comprehensive and detailed way compared to a quantitative approach [66]. With this in mind, we developed an interview guideline with three focus areas.

At the beginning, in the first question block, the interviewees were asked about the effects of CC on the IT market in Germany. The questions were intended to provide general information about the positions of the experts in the company to evaluate their expertise, the company itself, the target customer group, and the performance spectrum of the offered cloud services. In addition, the relevance of partnerships in the cloud value network was addressed.

In the second block of questions, we focused on the experts' perceptions and assessments of the current requirements for and barriers to using cloud technology, which are perceived by customers during the contact and sales phase. For this reason, we asked about the structure and design of the sales process as well as the existing sales channels. Furthermore, the interviewees were asked to ascertain the extent to which there are differences between long-time and first-time cloud users and among different contact persons in the company.

The third block was designed to identify the existing measures that are used by the CSPs to minimize barriers and derive recommendations or success factors that are appropriate for building a trusting relationship. Finally, the experts were asked to evaluate the changes in the $\mathrm{CC}$ sales process and the general conditions for CSPs. 
In preparing the interview guidelines, we followed the established research guidelines of [67]. Based on several pre-tests (with various researchers from the responsible institutions and a small sample of practitioners), the interview guidelines were adjusted. Afterwards, the participants for the investigation were selected. As mentioned above, we focused on the German CSP market as a first step. This limitation was imposed to control for cultural factors of influence and regulatory differences. Potential experts were contacted through personal messages and a posting in a forum on the Xing platform (www.xing.com). In addition, the Amadeus database was used to identify 188 companies that matched our requirements. All of them were contacted via e-mail. In sum, a total of 210 individuals were contacted, of whom 16 agreed to participate in our interview study. The interviews were conducted between the 9th and 20th of January 2017. Each interview took approximately 30$45 \mathrm{~min}$. Since the interviews were conducted by telephone, a digital recording was the most suitable method for preventing the loss of data. The participants had been informed of the digital recording in advance to ensure that consent to participate in the interview was accompanied by permission to record. Afterwards, the interviews were transcribed to analyze the collected material.

\section{Data analysis}

For the interpretation of the verbal data that are derived from the interviews, qualitative content analysis is suitable for gaining access to the subjective perceptions of the interviewees. Qualitative content analysis enables the systematic analysis of the transcribed interviews by processing the material step by step with theory-based category systems [68]. The goal of qualitative content analysis is the elaboration of meanings, which are represented by categories $[69,70]$.

Due to the focus and the subject of our investigation, we found that deductive categorization was appropriate [70]. For this reason, we followed the deductiveinductive sequence of qualitative content analysis that was proposed by Gläser and Laudel [67], which is based on essential basic forms of interpretation, as described by Mayring $[68,70]$. The coding was carried out with the software MAXQDA (release 12.2.1).

Extraction, which refers to the removal of the relevant information from the text and its assignment to appropriate categories, was both the focus and the initial step. The category system was prepared in advance based on conceptual foundations and preliminary considerations of prior research and the interview guideline. This category system is not final but allows continuous adaptation during the entire analysis [67]. The coding was performed by one of the authors and a subset of the coded material was checked by another author. This resulted in only minor coding conflicts that could be easily resolved.

Following the principle of extraction, all transcribed interviews were checked for relevant information, which was again assigned to the existing top and subcategories, with new, previously unrecognized categories being added during the extraction. In the second step, the extracted information is processed by identifying redundancies and contradictions and by placing the material in a corresponding structure for analysis. Following this step, the category system was subjected to a reexamination by the authors, and, if necessary, the top and subcategories were separated or summarized and renamed. The final step was the analysis of the structured material. This enabled the identification of the relationships between reconstructed cases [67].

\section{Selected study results Study participants}

We interviewed nine managing directors (MDs), five sales representatives (SRs), one business developer (BD), and one department manager (DM), who were all from German CSPs. The majority of the MDs were the founders of their respective companies. To differentiate the responses according to company size, the companies were grouped according to number of employees. According to the definition of small- and medium-sized enterprises (SMEs) from the European Commission [71], the sample is composed of four micro-enterprises $(<10$ employees), six small enterprises ( $<50$ employees), three medium-sized enterprises ( $<250$ employees), and three large companies ( $>249$ employees), as shown in Table 2.

With regard to the offered cloud services, the following structure emerges: seven companies offer SaaS and six companies provide IaaS. Two companies offer PaaS and one company is active only in cloud consulting. However, some of the companies provide at least two service models, with all combinations of IaaS, PaaS, and SaaS occurring, as listed in Table 1. A distinction can be made between companies that exclusively offer services that are provided by larger partners and companies that develop and provide their own services; some companies are a combination of these two variants. It is also possible that the companies themselves purchase cloud services in the role as aggregator or integrator from other vendors and then offer these products as white-labeled products under their own brand. This means that CSPs can take several roles in a value network. For this reason, we have assigned roles to the interviewed companies within the value network of $\mathrm{CC}$ according to the network structure that was suggested by Böhm et al. [27], as shown in Fig. 1. 
Table $\mathbf{2}$ Overview of interviewees

\begin{tabular}{|c|c|c|c|c|}
\hline ID & Position & $\begin{array}{l}\text { Number of } \\
\text { employees }\end{array}$ & $\begin{array}{l}\text { Primary cloud } \\
\text { service provided }\end{array}$ & $\begin{array}{l}\text { Additional cloud } \\
\text { services provided }\end{array}$ \\
\hline P01 & $\mathrm{MD}$ & $<10$ & SaaS & - \\
\hline P02 & $\mathrm{MD}$ & $<50$ & SaaS & - \\
\hline P03 & $\mathrm{MD}$ & $<250$ & laas & PaaS \\
\hline P04 & $\mathrm{MD}$ & $<10$ & Cloud Consulting & - \\
\hline P05 & $S R$ & $<50$ & laas & - \\
\hline P06 & $\mathrm{MD}$ & $<50$ & PaaS & SaaS, laas \\
\hline P07 & $\mathrm{MD}$ & $<10$ & SaaS & - \\
\hline P08 & $\mathrm{MD}$ & $<10$ & SaaS & - \\
\hline P09 & $\mathrm{DM}$ & $<250$ & SaaS & - \\
\hline P10 & $\mathrm{MD}$ & $<50$ & laaS & SaaS \\
\hline P11 & $\mathrm{MD}$ & $<50$ & laas & - \\
\hline P12 & $\mathrm{BD}$ & $>249$ & laas & SaaS \\
\hline P13 & $S R$ & $>249$ & SaaS & - \\
\hline P14 & $S R$ & $>249$ & SaaS & laaS \\
\hline P15 & $S R$ & $<50$ & laas & - \\
\hline P16 & SR & $<250$ & PaaS & SaaS, laas \\
\hline
\end{tabular}

$B D$ Business developer, $D M$ Department manager, $M D$ Managing director, $S R$ Sales representative

In the following, the statements of the interviewees, if not explicitly characterized otherwise, refer to all sectors and company sizes since no restrictions were made with respect to their customers.

Partnerships in the cloud value network were regarded as extremely important by $50 \%$ of the interviewees. Many of the companies have partnerships with large cloud providers, including Microsoft, Amazon, TSystems, Oracle, Salesforce, and SAP. In addition, there are partnerships with dealers and agencies, which distribute the cloud services of the interviewed companies and, therefore, cooperate in a complementary manner. The interviewees also stated further advantages of partnerships, such as not having to cover all necessary cloud services and models on their own (P02, P06, P10, P14, P15, P16).

\section{Customer comprehension, requirements and barriers as viewed by CSPs and the design of customer contact Comprehension of cloud services}

Considering the providers' perspective of the customers' general comprehension of cloud services, it should be noted that the term cloud has already arrived at companies of all industries and sizes (P01, P05, P10). However, the level of information and understanding varies across companies. It was stated by $25 \%$ of the interviewees that CSPs often have to address difficulties on the customer side with respect to their understanding of technical and legal issues. Differences in the need for information and understanding between user companies and companies that are not yet using a cloud service were detected by only one of the participants (P15). While large companies are more open-minded regarding cloud solutions, the interviewees identified at least as frequently medium-sized enterprises (which are larger enterprises within this cluster) as a target group. Furthermore, many companies, especially larger enterprises, often have profound and detailed questions regarding data protection and data security.

However, there are, for instance, differences with regard to contact persons in the company. IT employees are more knowledgeable in CC. Thus, they are more easily convinced of cloud benefits. However, the pressure to use cloud services arises from the operational departments and the management. At those company levels, as a consequence, a lack of comprehension arises. As a result, there is a higher need to clarify the functionalities and benefits of cloud services for non-IT departments. Therefore, CSPs are forced to convince the upper management of the rationale, profitability, and robustness to security failure instead of using detailed technical explanations. Table 3 provides selected sample statements of the interviewees regarding their comprehension of cloud services.

\section{Design of the sales processes}

The majority of interviewed CSPs (85\%) rely on direct sales, including online sales. Likewise, partnerships with dealers and marketing through sales partners were mentioned (62\%), which, from the vendors' point of view, also count as customers of direct sales. Regarding online sales, the interviews showed that some CSPs allow direct ordering through a website (P02, P05, P07). Therefore, direct contact between the customer and the provider is

Table 3 Quotes related to the comprehension of cloud services (translated by the authors)

\begin{tabular}{l} 
ID Quote \\
\hline P05 There's always the question of who you talk to in the company. Is \\
it rather the managing director or is it the IT representative? This is \\
a big difference, because you can assume that of course an IT \\
administrator or someone who works in the IT department already \\
had more points of contact with it [cloud computing]. \\
P08 The first barrier is to understand the process-related or the tech- \\
nical aspect of what this system makes possible at all. \\
P11 I believe that today, I am absolutely convinced, that there is still \\
the need for some people to find out what is hidden behind the \\
phrase cloud. \\
P12 If I can argue the statements in descending order of frequency, \\
the main topic is security, data privacy, legislation, a topic where \\
many people cannot talk about it and present it as a defensive \\
reaction. \\
P15 Some companies or business owners do not yet understand that \\
the data is isolated within the cloud and they sometimes believe, \\
the cloud is like sharing a hard disk; you can get customer data or \\
data from other users.
\end{tabular}


not necessary. However, most experts described direct contact with customers as more profitable, which is why one expert said that business is better carried out between people (P13). The most common ways to get into contact with the customers are e-mail, telephone, and personal meetings. Moreover, CSPs rely either on their existing customers to provide cloud services or on existing enterprise group customers. Once again, sales and distribution are positively influenced by the partnerships, in that the network serves both to recommend the cooperating partners to customers and to attract new customers.

In addition, some companies outsource the majority of the sales activities to agencies and sales partners (P09, P13, P14) who advise customers. The actual transactions are carried out via the partner. In this context, some of the interviewees indicated that there is a certain dependency on the partners. Many experts (43\%) mentioned the use of social networks, blogs and newsletters to provide information. Online seminars and discussions were mentioned as additional possibilities. Special attention in the sales process is necessary to identify customers who need to be more specifically addressed through a sales team, such as through a presales team. In the actual sales phase, the companies rely on personal conversations, in which employees with different professional competencies are involved. In this context, the goal of the CSPs is to satisfy the customer's needs and to provide individual advice and solutions. Regular exchange and contact with the customers seems just as important for the providers. Following the implementation of the project, the provider initiates so-called "follow-up calls" or regular status discussions to identify new projects or to expand existing projects. Table 4 provides selected sample statements of the interviewees regarding the design of the sales processes within their company.

\section{Security concerns, ownership, and loss of power}

Threats or barriers that have repeatedly been raised by the experts are related to the need for clarification and

Table 4 Quotes related to the design of the sales processes (translated by the authors)

ID Quote

P05 According to the traditional sales channels we have built a Web to Sales process. This means that the customer registers himself with us on the platform and can basically setup and use everything on his or her own.

P09 We communicate our offers via the Internet. We have our own homepage where basically everything is presented. We have a blog, we are on different social media channels, Xing, Linkedln, Twitter, Google Plus, YouTube where we also provide information and work actively. In addition, we have a newsletter and are on these referential cloud marketplaces.

P13 We have a classic channel model which means that we only sell through specialized retailers, resellers and system vendors. the differences among their respective contacts. Customers' demands for information about the functionality of the cloud reflect their concerns with respect to data security, privacy, and data location. The interviewees see concerns over security as the biggest obstacle for potential users of cloud services, whereas compliance requirements were rarely mentioned in the interviews. With regard to the physical location of the data, it was clear from the respondents' statements that customers demand, at best, a German, but at least a European data center location (P04, P08, P09, P15, P16). Data security (stated by $81 \%$ of the interviewees) is another important requirement in this context because losing data and experiencing unauthorized access through security gaps are huge concerns. However, some of the potential users are aware that cloud solutions can ensure a higher level of security compared to their own IT landscape. Therefore, some experts stated that security concerns are no longer an insurmountable obstacle (P03, P06).

The identified differences among the contact partners explain the fears regarding loss of power and the resulting ownership. Although IT staff are better educated in $\mathrm{CC}$ and easier to convince of the benefits, some do not want to use cloud-based services. From the interviewees' point of view, the fear of losing power in their position at the company, especially within the IT department, is reflected, especially when moving into the cloud is "used" to reduce the existing IT headcount (P01, P03, P04, P12, P13, P14). Therefore, some of the employees even fear losing their jobs by incorporating cloud services into their company's infrastructure. The retention of property and the loss of control and power are also associated with another obstacle that was identified in the interviews: the fear of being too dependent on a CSP (P01, P05, P07, P09, P14). In this context, potential users are concerned about the depreciation of existing systems, which will no longer be required or compatible with the existing companyinternal solutions. Other aspects, according to the experts, are the need for a simple migration and many of the "typical" cloud characteristics, e.g., scalability, flexibility, stability, and the ability to focus on core processes. Table 5 provides selected sample statements of the interviewees especially with focus on security aspects and the loss of power when companies implement and use cloud services.

\section{Providers' actions and challenges}

The following measures explicitly refer to the identified barriers. In addition, necessary competences and activities can be derived from the information of the respondents to build a relationship of trust between provider and customer. Currently, general concerns of potential users and their need for information about the functionality of the cloud are usually encountered with 
Table 5 Quotes related to security concerns, ownership, and loss of power (translated by the authors)

\begin{tabular}{l} 
ID Quote \\
\hline P04 Typically, the IT manager is not necessarily euphoric when it \\
comes to cloud services because, of course, he is deprived of a \\
certain position of power that he has held so far. \\
P05 Basically, the most important issue is always the issue of trust. The \\
subject of data security, the subject of encryption, for example, is \\
an essential topic, especially in Germany. \\
P09 What still plays a major role is the handling of the data at the end \\
of the contract. That means the data is in our cloud. How do they \\
get out or do they even get out? \\
P14 The obstacle number one in Germany is first of all the \\
fundamental fear, everything that is not in the own company is \\
evil. So, I give away what was mine before, i.e. the fear of the \\
uncertainty - what happens to my data, where are my data?
\end{tabular}

information and consulting from the provider. Therefore, $34 \%$ of the interviewees confirmed that raising awareness plays a large part in the sales process and occurs before the actual transaction. It may be helpful to indicate the added value and benefits of the cloud (e.g., economic aspects), especially when the management board should be convinced (P05, P08, P16).

Another measure for counteracting users' security concerns and demands regarding German data location is the use of directly rented or self-hosted data centers in Germany (P08, P13, P15, P16). Furthermore, CSPs try to show to potential customers that financial aspects should not be critical reasons for deploying a cloud solution. Regarding references of CSPs, many different variants are used to emphasize customer satisfaction. Use cases, quotes on the website, and success stories were most often used. Of particular importance were the interviewees' statements that the focus on references from German customers or references within the same industry sector is meaningful since references from abroad seem to carry less weight for German customers (P03, P12, P14, P15). The relevance of certification is also confirmed by $56 \%$ of the experts, which mainly refers to the certification of partners (primarily IaaS). The experts usually gave no examples of certificates or seals. They considered the necessary competencies and activities for establishing a customer relationship equally essential. A particularly important measure of customer engagement is communication, which should have the aim of building a trusting relationship with the customers. Personal contact and dialogue are regarded as necessary to be able to address the concerns of customers directly. This can be supported by the creation of typified marketing materials to meet the requirements of the various contact persons in the company.

As an additional measure for improving communication through transparency and openness, providers rely on the continuous provision of information regarding maintenance, updates, and outages. The provision of demo and trial versions and free capacity at the beginning of the business relationship is also used as a trustbuilding measure. Furthermore, training courses are suitable for strengthening confidence in technology and the involvement of users leads to better acceptance in user companies.

\section{Discussion and implications}

One of the main challenges that arises from the statements of the experts is addressing customers and building a relationship of trust. Potential users are characterized by a high degree of skepticism. This is why there are multiple requirements and obstacles that must be addressed by the provider, especially in customer acquisition. Given the increasing use of cloud services, especially in large companies, the internationalization of the market and the ongoing technological development, security concerns and requirements are some of the most important aspects that providers should address now and in the future. The interviewees see security as the biggest obstacle potential users of cloud services, whose statements largely correspond to the literature (e.g., [23, 34, 50, 72, 73]).

However, when using cloud services, the CSPs confirmed that the customer requirements, such as transparency and focus on core competencies, outsourcing of services, including operations and support, and cost reduction can be achieved through the use of cloud services. This is in line with benefits that have been identified in the cloud literature (e.g., $[5,6,8,14]$ ).

Regarding the change in the sales processes, the essential challenges can be identified as the increase in complexity and the simultaneous simplification of certain sales activities. In addition to the higher staff costs that result from the need to explain the service, providers must increasingly involve solution experts with the technical and legal know-how to support the sales team to increase the trust of customers in the providers and their cloud services. At the same time, we identified a simplification of the distribution processes through the growing importance of online channels, which allows customers to obtain services without vendor contact and, ultimately, possesses the characteristics of ondemand self-services. Furthermore, the use of training courses to increase user acceptance, continuous interaction with the customers and the provision of necessary information on updates and outages are of enormous importance. These factors provide a reason for continuous customer contact and can strengthen the credibility of the providers. It also seems necessary to take the fears of IT staff seriously (see also [51]) and reduce them by stressing the importance of a cloud strategy that does 
not imply IT headcount reduction but instead a shift of tasks towards more cooperation and collaboration with providers. Accordingly, the following challenges were identified in the sales processes (see Table 6).

Thus, the selection, monitoring, and integration of the services must be considered. However, CSPs can only have a limited impact because the design of the internal organization is the responsibility of the managing directors of the user companies. Another challenge results from the customer demands for both individual solutions and interoperability, which, in turn, can minimize dependencies on the provider. Users are concerned that they will not be able to change vendors without much effort, which will not meet their requirements for interoperability and portability [74]. The challenge for providers is to find a balance between standardization and meeting customer-specific requirements.

Other aspects, according to the experts, are the need for a simple migration as well as many of the cloud characteristics, which are often mentioned in the literature (e.g., $[5,20,36,49,75])$ and represent the essential advantages of cloud service solutions. These include scalability, flexibility, stability, and the ability to focus on core processes, as not only the development but also the operation of the IT services can be outsourced. However, the preparation and migration of the data into the cloud are cost-intensive and time-consuming. Furthermore, references and certifications can be considered, which both have already been identified as confidence-building measures in the literature $[23,76]$ and comply with the user requirements for the transparency and trustworthiness of the CSP.

Placing importance on transparency and professionalism in customer communication also has a positive impact on customer confidence [77]. This was confirmed by the statements of the experts, who named professionalism as a key competence. This includes expertise, problem-solving competence, and reliability and allows providers to comply with the need to competently address technical and legal aspects of the cloud in the customer conversation. This is achieved, for example, by a

Table 6 Challenges in sales processes

\section{Challenges}

Necessity of improving customers' cloud understanding, especially regarding the technical and legal aspects, and compliance with this in the sales processes

Provision of a sufficient number of qualified employees and/or an increase in the number of employees in the sales department, along with the need for appropriate technical knowledge among the sales staff

Addressing the appropriate contact person and adapting to the shift of skills and drivers in the user company

Continuous support of business relationships through value-adding and additional services solutions expert, who will support the sales staff in the consulting process and meetings with potential customers.

In addition, the participants stated their opinions on future challenges and described the changes in the market and in their own business models as major challenges. The experts confirmed that they still see a large growing potential in the cloud market (as also supported by several studies; e.g., $[17,21,25,78,79])$. Thus, additional CSPs will become established in the market. However, consolidation will occur in the long term. Moreover, the experts assume that the requirements for cloud services will increase, especially because the potential users will have more choices. They emphasized the advantages of partnerships, which enable the provision of specialized solutions by also providing the necessary resources and additional services to the providers through partners. In this respect, the influence of the already established large cloud providers will continue to intensify. This also means that customers probably cannot avoid using one or more cloud solutions in the medium to long term.

In summary, we identified the following aspects (see Table 7) as current and future challenges for CSPs based on the interviews and in combination with the existing literature.

\section{Conclusions and future aspects}

Our study revealed different perspectives on $\mathrm{CC}$ from business experts who are working for CSPs. The increasing use of cloud services causes higher competitive pressure on the IT market. Now more than ever, CSPs are forced to know and manage current and future challenges. Therefore, the aim of this paper was to identify the specific challenges of CSPs that are located in Germany.

\section{Table 7 Current and future challenges for CSPS}

\section{Challenges}

Building trust in the technology and functionality of the cloud by reducing security concerns and increasing personal trust

relationships, especially through professional behavior

Addressing fears of IT staff and convincing them of the importance of a cloud strategy, including the necessary IT skills

Reasonable balance between customization and standardization of services to address the fear of a vendor lock-in and to improve interoperability

Continuously questioning and optimizing one's own business model and service portfolio
More focus on compliance requirements, service-level agreements, and service provision at data centers in Germany or at least in Europe (especially when focusing on German customers)

Implementation of training courses and ongoing provision of relevant information

Competitive pressure (also price pressure) through an increasing number of providers

Selection of appropriate partnerships to provide specialized solutions and value-added services. 
Our research contributes to practice and IS research. From a researcher's point of view, our paper contributes to cloud research by summarizing the existing literature, especially regarding cloud service selection, and by identifying current and future challenges of CSPs, especially from their perspective. We found that CSPs already address relevant requirements and barriers that are identified in several existing publications. However, nearly all of the literature focuses on the requirements and the selection process of CSPs from the users' perspective. The perspective of the provider is rarely discussed in the literature. Nevertheless, understanding the perception of the providers and their actions/measures is essential for future research activities in the field of cloud service selection. Matching and linking the users' perspectives with the providers' measures will enhance the development of a holistic selection approach for future cloud projects. Therefore, our contribution to research is also the identification of this missing integration.

For practice/practitioners, our interview study provides insights into specific actions/measures of CSPs to address users' concerns and expectations. From this practical point of view, through the analysis of interviews with business experts from 16 German CSPs, we revealed the experiences and subjective assessments of the experts. Thus, we presented the views of the CSPs. We identified current customer requirements and barriers to using cloud services from the providers' viewpoint (RQ 1) and presented actions of and threats to CSPs in meeting the needs and constraints of the customers (RQ 2). Finally, we derived current and future challenges for CSPs in dealing with customer requirements and barriers by addressing the root causes of those obstacles (RQ 3). Practitioners can compare these results with their own actions and derive further steps for their own companies.

As in most empirical studies, our work is limited in multiple ways. Due to our qualitative study approach, the obtained results possess limited statistical generalizability. However, the applied method allowed us to identify important details and obtain deep insights into the experience of CSP business experts, which was the main focus of this first study in our long-term research project. Another limitation is that the interviewees' origins are limited to German CSPs, which implies that the study reflects the situation in only one country. German specifics could have influenced the results. Furthermore, our study pertains mostly to smalland medium-sized CSPs. Therefore, including a higher number of larger CSPs would widen the results of our investigation.

Based on these results and limitations and given the emerging nature of $\mathrm{CC}$, we foresee several future research opportunities. An interesting direction would be to apply our study approach to the CSPs of other countries and with more variety in terms of company size. Another aspect will be shifting the perspective to $\mathrm{CC}$ user companies to compare the experiences and findings with those of this study. Moreover, further research is required on a conceptual level, e.g., on procedure models for meeting the requirements and criteria of user companies and CSPs, to design a holistic selection approach.

\begin{abstract}
Abbreviations
BD: Business Developer; BITKOM: Bundesverband Informationswirtschaft, Telekommunikation und neue Medien; BSI: Bundesamt für Sicherheit in der Informationstechnik; CC: Cloud Computing; CSP: Cloud Service Provider; DM: Department Manager; EU: European Union; FAGI: Function, Auditability, Governability and Interoperability; laaS: Infrastructure as a Service;

ICT: Information and communication technology; IS: Information Systems; ISACA: Information Systems Audit and Control Association; IT: Information Technology; MD: Managing Director; NIST: National Institute of Standards and Technology; PaaS: Platform as a Service; PwC: PricewaterhouseCoopers; RQ: Research Question; SaaS: Software as a Service; SMEs: Small- and Medium-sized Enterprises; SR: Sales Representatives
\end{abstract}

\section{Acknowledgements}

We are thankful to the reviewers for their valuable feedback and comments for improving the quality of the manuscript.

\section{Funding}

We acknowledge publication support by the German Research Foundation and the Open Access Publication Funds of the TU Dresden.

\section{Availability of data and materials}

Not applicable.

\section{Authors' contributions}

All listed authors have made substantial intellectual contributions to the research and the manuscript. $\mathrm{RH}$ was responsible for the overall research, including manuscript writing, analysis and interpretation of the study results. $\mathrm{AP}$ and $\mathrm{CL}$ contributed to the design of the questionnaire. AP conducted the expert interviews. CL contributed to the design of the methodology and participated in the critical and technical revisions of the paper, including final processing. All authors read and approved the final manuscript.

\section{Authors' information}

Raoul Hentschel (RH) is PhD student and research assistant at the Chair of Information Systems, esp. Information Systems in Manufacturing and Commerce (ISIH) at the Technische Universität Dresden. He is currently working on an appropriate taxonomy/decision support for Cloud Service Provider selection for small- and medium-sized enterprises. Prior to that, he obtained his diploma in Business Informatics at Technische Universität Dresden. His current research interests are cloud computing and cloud services, value-added networks of cloud senvice providers and cloud enterprise systems. Dr. Christian Leyh (CL) is currently working as post-doc at the Chair of Information Systems; esp. IS in Manufacturing and Commerce (ISIH) at the Technische Universität Dresden. He obtained his PhD in 2014, focusing on enterprise systems in small- and medium-sized enterprises. Prior to that, he graduated from the University of Applied Science Schmalkalden information systems program and completed his Master's Degree in business and engineering at the Steinbeis University Berlin. Currently, he teaches in both the undergraduate and graduate IS programs. His research interests are centered within the field of digitization and digitalization, esp. focusing on measuring the digitalization levels of companies from different organizational perspectives. Anne Petznick (AP) studied at Technische Universität Dresden and wrote her Master's Thesis at the Chair of Information Systems; esp. IS in Manufacturing and Commerce (ISIH) and obtained her master's degree in Business Management. During her studies, she supported a cloud project at the Chair of Information Systems, esp. Information Systems in Manufacturing and Commerce $(I S \mid H)$. 


\section{Competing interests}

The authors declare that they have no competing interests.

\section{Publisher's Note}

Springer Nature remains neutral with regard to jurisdictional claims in published maps and institutional affiliations.

Received: 12 November 2017 Accepted: 1 March 2018

Published online: 12 March 2018

\section{References}

1. Châlons C, Dufft N (2016) Die Rolle der IT als Enabler für Digitalisierung. In: Abolhassan F (ed) Was treibt die Digitalisierung? Warum an der Cloud kein Weg vorbeiführt. Springer, Wiesbaden, pp 27-37

2. Yanosky R (2008) From users to choosers: the cloud and the changing shape of Enterprise Authority. In: Katz RN (ed) The tower and the cloud. Educause E-book, campanile. University of California, Berkeley, pp 126-136

3. Armbrust M, Fox A, Griffith R et al (2010) A view of cloud computing. Commun ACM 53:50-58. https://doi.org/10.1145/1721654.1721672

4. Ragowsky A, Licker P, Miller J et al (2014) Do not call me chief information officer, but chief integration officer. A summary of the 2011 Detroit ClO roundtable. Commun Assoc Inf Syst 34:1333-1346

5. Wang N, Liang H, Jia $\mathrm{Y}$ et al (2016) Cloud computing research in the IS discipline: a citation/co-citation analysis. Decis Support Syst 86:35-47. https://doi.org/10.1016/.j.dss.2016.03.006

6. Petter S, Delone W, Mclean ER (2012) The past, present, and future of "IS success". J Assoc Inf Syst 13:341-362

7. Durao F, Carvalho JFS, Fonseka A, Garcia VC (2014) A systematic review on cloud computing. J Supercomput 68:1321-1346. https://doi.org/10.1007/ s11227-014-1089-x

8. Marston S, Li Z, Bandyopadhyay S et al (2011) Cloud computing - the business perspective. Decis Support Syst 51:176-189. https://doi.org/10. 1016/j.dss.2010.12.006

9. Weinhardt C, Anandasivam A, Blau B et al (2009) Cloud computing - a classification, business models, and research directions. Business \& Information Systems Engineering 1:391-399. https://doi.org/10.1007/s12599009-0071-2

10. Cooper J, Bradley DB (2014) Cloud Computing's selection and effect on small business. Entrep Exec 19:87-95

11. Schneider S, Sunyaev A (2015) CloudLive: a life cycle framework for cloud services. Electron Mark 25:299-311. https://doi.org/10.1007/s12525-015-0205-y

12. Cellary W, Strykowski S (2009) e-Government Based on Cloud Computing and Service-oriented Architecture. In: Proceedings of the 3rd International Conference on Theory and Practice of Electronic Governance 2009

13. Yang $\mathrm{H}$, Tate M (2012) A descriptive literature review and classification of cloud computing research. Communications of the Association of Information Systems 31:35-60 10.1.1.261.3070

14. Venters W, Whitley EA (2012) A critical review of cloud computing: researching desires and realities. J Inf Technol 27:179-197. https://doi.org/ 10.1057/jit.2012.17

15. Leimeister S, Riedl C, Böhm M, Krcmar H (2010) The business perspective of cloud computing: actors, roles, and value networks. In: proceedings of 18th European conference on. Inf Syst 2010

16. Vaquero LM, Rodero-Merino L Caceres J, Lindner M (2008) A break in the clouds: towards a cloud definition. ACM SIGCOMM Computer Communication Review 39:50-55. https://doi.org/10.1 145/1496091.1496100

17. Schneider S, Sunyaev A (2016) Determinant factors of cloud-sourcing decisions: reflecting on the IT outsourcing literature in the era of cloud computing. J Inf Technol 31, 31(1). https://doi.org/10.1057/jit.2014.25

18. Mell P, Grance T (2011) The NIST definition of cloud computing. National Institute of Standards and Technology. Nist Special Publication:800-145

19. Armbrust M, Fox A, Griffith R et al (2009) Above the Clouds: A Berkeley View of Cloud Computing. In: Technical Report No. UCB/EECS-2009-28, Electrical Engineering and Computer Sciences. University of California at Berkeley, Berkeley, CA

20. Snaith B, Hardy M, Walker A (2011) Emergency ultrasound in the prehospital setting: the impact of environment on examination outcomes. Emerg Med J 28:1063-1065. https://doi.org/10.1136/emj.2010.096966

21. Chang V, Walters RJ, Wills G (2015) Delivery and adoption of cloud computing Services in Contemporary Organizations. IGI Global
22. Zhang Q, Cheng L, Boutaba R (2010) Cloud computing: state-of-the-art and research challenges. J Internet Serv and Appl 1:7-18. https://doi.org/10. 1007/s13174-010-0007-6

23. Vehlow M, Thier K-F (2015) Cloud Governance in Deutschland - eine Standortbestimmung. PricewaterhouseCoopers AG

24. Kappelman L, Luftman J, Mclean E, Johnson V (2013) Key issues of IT organizations and their leadership: the 2013 SIM IT trends study. MIS Q Exec 12:227-240. https://doi.org/10.1108/02635570910926564

25. Kappelman L, McLean E, Johnson V et al (2017) The 2016 SIM IT trends study. MIS Q Exec 16:55-83

26. Riedl C, Böhmann T, Leimeister JM, Krcmar H (2009) A framework for analysing service ecosystem capabilities to innovate. In: Proceedings of the 17th European Conference on Information Systems, Verona, Italy June 8th-10th 2009

27. Böhm M, Koleva G, Leimeister $S$ et al (2010) Towards a generic value network for cloud computing. In: Altmann J, OF R (eds) Economics of grids, clouds, systems, and services: 7th international workshop 2010. Springer Berlin Heidelberg, pp 129-140

28. Münzl G, Pauly M, Reti M (2015) Cloud Computing als neue Herausforderung für Management und IT. Springer Vieweg, Berlin, Heidelberg

29. Heidkamp P, Pols A (2016) Cloud-monitor 2016: cloud-computing in Deutschland - status quo und Perspektiven. KPMG AG

30. Zacher M (2017) Cloud Computing in Deutschland 2017. IDC Central Europe $\mathrm{GmbH}$, Frankfurt

31. Vehlow M, Golkowsky C (2011) Cloud computing navigation in der Wolke. PricewaterhouseCoopers AG

32. BITKOM (2010) Cloud Computing - Was Entscheider wissen müssen. In: Bundesverband Informationswirtschaft, Telekommunikation und neue Medien e.V. BITKOM, Berlin

33. Gonzalez N, Miers C, Redígolo F et al (2012) A quantitative analysis of current security concerns and solutions for cloud computing. Journal of Cloud Computing: Advances, Systems and Applications 1:11. https://doi.org/ 10.1186/2192-113X-1-11

34. Tang C, Liu J (2015) Selecting a trusted cloud service provider for your SaaS program. Computers and Security 50:60-73. https://doi.org/10.1016/..cose. 2015.02.001

35. Rong C, Nguyen ST, Jaatun MG (2013) Beyond lightning: a survey on security challenges in cloud computing. Comput Electr Eng 39:47-54. https://doi.org/10.1016/i.compeleceng.2012.04.015

36. Benlian A, Hess T (2011) Opportunities and risks of software-as-a-service: findings from a survey of IT executives. Decis Support Syst 52:232-246. https://doi.org/10.1016/j.dss.2011.07.007

37. Low C, Hsueh Chen Y (2012) Criteria for the evaluation of a cloud-based hospital information system outsourcing provider. J Med Syst 36:3543-3553. https://doi.org/10.1007/s10916-012-9829-z

38. Martens B, Teuteberg F (2012) Decision-making in cloud computing environments: a cost and risk based approach. Inf Syst Front 14:871-893. https://doi.org/10.1007/s10796-011-9317-x

39. Messerschmidt CM, Hinz O (2013) Explaining the adoption of grid computing: an integrated institutional theory and organizational capability approach. J Strateg Inf Syst 22:137-156. https://doi.org/10.1016/jj.jis.2012.10.005

40. Habib SM, Hauke S, Ries S, Mühlhäuser M (2012) Trust as a facilitator in cloud computing: a survey. Journal of Cloud Computing 1:19. https://doi. org/10.1186/2192-113X-1-19

41. Clemons EK, Chen Y (2011) Making the decision to contract for cloud services: managing the risk of an extreme form of IT outsourcing. In: In: proceedings of 44th Hawaii international conference on system sciences

42. Repschlaeger J, Zarnekow R, Wind S, Klaus T (2012) Cloud requirement framework: requirements and evaluation criteria to adopt cloud solutions. In: proceedings of 20th European conference on Information Systems 2012

43. Hetzenecker J, Kammerer S, Zeiler V, Amberg M (2012) Anforderungen an cloud computing Anbieter. In: Multikonferenz Wirtschaftsinformatik 2012 (MKWI), pp 539-550

44. Supriya M, Sangeeta K, Patra GK (2016) Trustworthy cloud service provider selection using multi criteria decision making methods. Eng Lett 24:1

45. Liu S, Chan FTS, Ran W (2016) Decision making for the selection of cloud vendor: an improved approach under group decision-making with integrated weights and objective/subjective attributes. Expert Syst Appl 55: 37-47. https://doi.org/10.1016/j.eswa.2016.01.059

46. Ouedraogo M, Mouratidis H (2013) Selecting a cloud service provider in the age of cybercrime. Computers and Security 38:3-13. https://doi.org/10.1016/ j.cose.2013.01.007 
47. Li C, Yanpei L, Youlong L (2016) Efficient service selection approach for mobile devices in mobile cloud. J Supercomput 72:2197-2220. https://doi. org/10.1007/s11227-016-1720-0

48. Benlian A, Koufaris M, Hess T (2010) The Role of Saas Service Quality for Continued Saas Use: Empirical Insights from Saas Using Firms. In: Proceedings of the 31st International Conference on Infomration Systems 2010

49. Hoberg P, München TU, Wollersheim J (2012) The business perspective on cloud computing - a literature review of research on cloud computing. In: proceedings of 18th Americas conference on Information Systems 2012

50. Walther S, Plank A, Eymann T et al (2012) Success factors and value propositions of software as a service providers - a literature review and classification. In: proceedings of 18th Americas conference on Information Systems 2012

51. Winkler T, Goebel C, Benlian A et al (2011) The Impact of Software As a Service on Is Authority - a Contingency Perspective. In: Proceedings of the 32nd International Conference on Informations Systems 2011

52. Low C, Chen Y, Wu M (2011) Understanding the determinants of cloud computing adoption. Ind Manag Data Syst 111:1006-1023. https://doi.org/ 10.1108/026355711111161262

53. Bhattacherjee A, Park SC (2014) Why end-users move to the cloud: a migration-theoretic analysis. Eur J Inf Syst 23:357-372. https://doi.org/10. 1057/ejis.2013.1

54. Oliveira T, Thomas M, Espadanal M (2014) Assessing the determinants of cloud computing adoption: an analysis of the manufacturing and services sectors. Information and Management 51:497-510. https://doi.org/10.1016/j. im.2014.03.006

55. Gupta P, Seetharaman A, Raj JR (2013) The usage and adoption of cloud computing by small and medium businesses. Int J Inf Manag 33:861-874. https://doi.org/10.1016/j.ijinfomgt.2013.07.001

56. Hsu PF, Ray S, Li-Hsieh YY (2014) Examining cloud computing adoption intention, pricing mechanism, and deployment model. Int J Inf Manag 34: 474-488. https://doi.org/10.1016/j.ijinfomgt.2014.04.006

57. Walterbusch M, Martens B, Teuteberg F (2015) A decision model for the evaluation and selection of cloud computing services: a first step towards a more sustainable perspective. International Journal of Information Technology \& Decision Making 14:253-285. https://doi.org/10.1142/S0219622015500054

58. IDC (2013) Deutsche Unternehmen wollen mit Cloud Services Geschäftsprozesse optimieren. IDC White Paper http://idc.de/de/ueber-idc/ press-center/54895-idc-studie-deutsche-unternehmen-wollen-mit-cloudservices-geschaftsprozesse-optimieren. Accessed 2 Oct 2016

59. BSI (2012) Sicherheitsempfehlungen für Cloud Computing Anbieter Mindestanforderungen in der Informationssicherheit. Bundesamt für Sicherheit in der Informationstechnik

60. Trenz M, Huntgeburth J, Veit D (2017) How to Succeed with Cloud Services? Business \& Information Systems Engineering OnlineFirst Article. https://doi. org/10.1007/s12599-017-0494-0

61. Labes S, Hanner N, Zarnekow R (2017) Successful business model types of cloud providers. Business \& Information Systems Engineering 59:223-233. https://doi.org/10.1007/s12599-016-0455-z

62. Sun L, Dong H, Hussain FK et al (2014) Cloud service selection: state-of-theart and future research directions. J Netw Comput Appl 45:134-150. https:// doi.org/10.1016/j.jnca.2014.07.019

63. Ermakova T, Erek K, Huenges J (2013) Cloud computing in healthcare - a literature review on current state of research. In: proceedings of the 19th Americas conference on Infomration Systems 2013

64. Repschläger J (2013) Entscheidungsfindung im Cloud Computing - Konzeption und Analyse eines Modells zur Anbieterauswahl. Dissertation, TU Berlin, Berlin

65. Türling F (2011) White Paper: Erfolgreiche Kundengewinnung in der Cloud. http://cloudecosystem.org/wp-content/uploads/2014/02/WhitePaper_FT_ DRUCK.pdf. Accessed 5 Dec 2016

66. Recker J (2013) Scientific research in information systems. Springer, Berlin Heidelberg

67. Gläser J, Laudel G (2010) Experteninterviews und qualitative Inhaltsanalyse als Instrumente rekonstruierender Untersuchungen. VS Verlag für Sozialwissenschaften, Wiesbaden

68. Mayring P (2002) Einführung in die qualitative Sozialforschung: Eine Anleitung zu qualitativem Denken. Beltz, Weinheim, Basel

69. Döring N, Bortz J (2016) Forschungsmethoden und Evaluation in den Sozialund Humanwissenschaften. Springer Gabler 1051. https://doi.org/10.1007/9783-642-41089-5
70. Mayring P (2015) Qualitative Inhaltsanalyse. Grundlagen und Techniken, Beltz, Weinheim

71. EU Commission (2005) The new SME definition - user guide and model declaration. European Commission

72. IDG (2016) 2016 Cloud Computing Survey, Executive Summary. IDG Communications, Inc

73. Thorenz L, Zacher M (2013) Cloud-computing: Neue Chancen für das outsourcing. In: Rickmann H, Diefenbach S, Brüning KT (eds) IT-Outsourcing: Neue Herausforderungen im Zeitalter von Cloud Computing. Springer, Berlin, pp 25-38

74. Repschläger J, Zarnekow R (2012) Erfolgskritische Faktoren und Kundensegmente im Cloud Computing. TU Berlin IKM Lehrstuhl, Berlin

75. Malladi S, Krishnan MS (2012) Cloud computing adoption and its implications for $\mathrm{ClO}$ strategic focus - an empirical analysis. In: proceedings of 33rd international conference on Infomration Systems 2012

76. Schneider S, Sunyaev A (2015) Gestaltungsempfehlungen für Cloud-ServiceZertifizierungen. In: Cloud-Service-Zertifizierung. Springer, Berlin, pp 63-68

77. Hofmann GR, Schumacher M (2014) Studie zur Akzeptanz von Cloud Computing - Neuauflage 2014. EuroCloud Deutschland_eco e.V, Cologne

78. Bartels A (2016) US tech market outlook for 2016 and 2017: cloud and business caution will slow growth. In: Forrester research, Cambridge

79. Riegel L, Schick M (2016) The German internet industry 2016-2019. Arthur D, Little GmbH, Frankfurt

\section{Submit your manuscript to a SpringerOpen ${ }^{\circ}$ journal and benefit from:}

- Convenient online submission

- Rigorous peer review

- Open access: articles freely available online

- High visibility within the field

- Retaining the copyright to your article

Submit your next manuscript at $>$ springeropen.com 